\title{
Management of Unstable Mandibular Denture With Neutral Zone Impression Technique
}

\author{
Janani Mahadevan ${ }^{1}$, Sabita M. Ram²
}

\begin{abstract}
Oral functions involve unique interplay of oral structures and muscles. Any interference with their movements by a denture would result in denture instability. If the denture is placed in a zone where the displacing forces of tongue, lips, cheeks and modiolus are balanced, then the denture will be retained more effectively during function. This zone is known as neutral zone. If the denture strays outside/inside the neutral zone it will be unstable during the activities such as talking, swallowing and mastication. The neutral zone technique is used to minimize the displacing forces of the surrounding structures. This is a case report in which neutral zone impression technique was used to solve the problem of denture instability.
\end{abstract}

Key Words: Instability, atrophic ridge, muscle function

\section{Introduction}

The copy technique is most commonly used for construction of complete dentures. This traditionally used technique serves an excellent role in most of the cases except in cases where the residual ridge resorption has led to highly atrophic ridge. It also gives unsatisfactory results in cases where the patient has been edentulous for an extremely long period thus leading to poor neuromuscular control exerted on the denture. An alternative technique may be used in treating such complex cases. ${ }^{1}$

Locating the neutral zone for the mandibular denture is one of the most important factors in achieving stability of the denture. Although the concept and the importance of the concept have been mentioned in the literature, very little has been written as to the techniques involved. ${ }^{2}$ The mandibular denture presents with most common difficulties with looseness being the most common complaint. ${ }^{3}$ This is because the mandible atrophies at a greater rate than the maxilla and has less residual ridge for retention and support. ${ }^{4}$ The neutral zone impression technique is most effective in patients who have had numerous unstable, unretentive mandibular complete denture. These patients usually have highly

1 Sr. Lecturer

2 Professor \& Head

Dept. of Prosthodontics

MGM Dental College \& Hospital, Navi Mumbai

Address for Correspondence

Dr. Janani Mahadevan

MGM Dental College

Kamothe, Navi Mumbai 410209

Mob: 9323686503

Email:drjananim@gmail.com atrophic mandible and there has been difficulty in positioning the teeth to produce a stable denture. This article aims to provide clinicians with the knowledge to use the technique.

\section{Neutral zone}

The neutral zone has been defined, "As the area in the mouth where during function, the forces of the tongue pressing outwards are neutralized by the forces of the cheeks and lips pressing inwards".

Sir Wilfred Fish first described the influence of the polished surfaces on retention and stability in $1931.6 \mathrm{He}$ described it as dead space which later came to be known as "NEUTRAL ZONE". ${ }^{7}$ Since that time there have been a number of techniques described in the literature, which have attempted to provide moulding of the neutral zone. Soft waxes, modeling compound \& tissue conditioners can be used for this procedure.

Buchman and Gelb, Lott and Levin, and Russel have described the use of waxes in locating the neural zone. Tench has suggested the use of modelling compound. ${ }^{2}$ Tissue conditioners can also be used. These soft, mouldable materials are placed in the mouth with patients performing actions with their lips and tongues, the idea being to capture in greater detail the actions of the lips, cheeks and tongue. These actions determine the tooth position and shape of polished surface. The aim is to produce a denture moulded by muscle function that is in harmony with its surrounding structures so enhancing stability and retention. ${ }^{1}$

\section{Case report}

A 52 years old female patient reported to the OPD with the chief complaint of loose mandibular complete 
denture. History revealed that the patient had been edentulous for the past 20 years. Patient had two sets of complete denture made earlier and with both the dentures patient had the problem of instability of mandibular denture.

Intra-oral examination revealed extremely strong mentalis and buccinator muscle which on activation led to narrowing of labial and buccal sulcus. Tongue showed uncoordinated movements. The patient had very uncertain pattern of mandibular closure. (Fig. 1\& 2)

Critical examination of previous denture showed the posterior teeth were positioned lateral to the crest of the ridge. The mandibular occlusal plane was also higher further adding to instability of mandibular denture.

It was therefore decided to use neutral zone impression technique to determine the optimum position of teeth and the contour of the polished surfaces of denture in harmony with the surrounding musculature. (Fig. $1 \& 2$ )

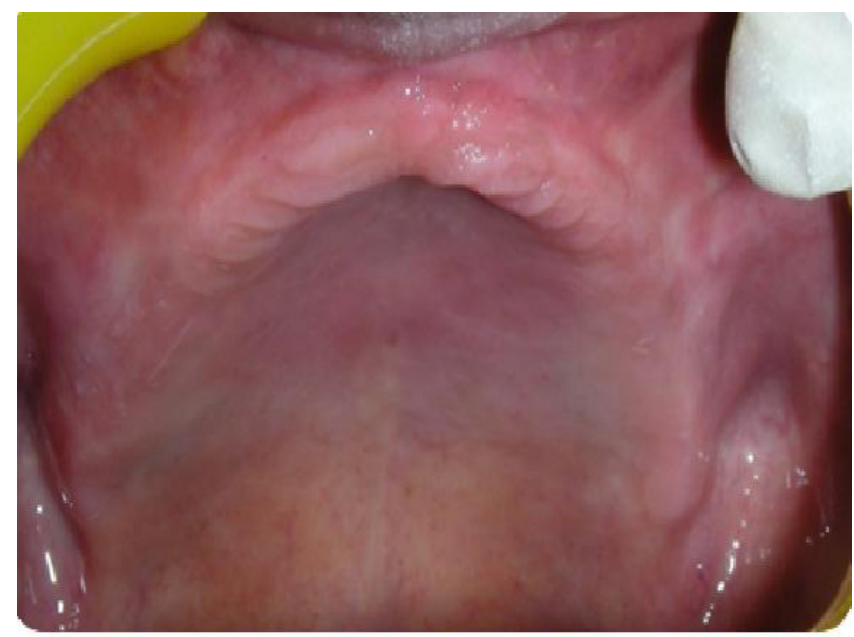

Fig 1. Edentulous maxillary arch

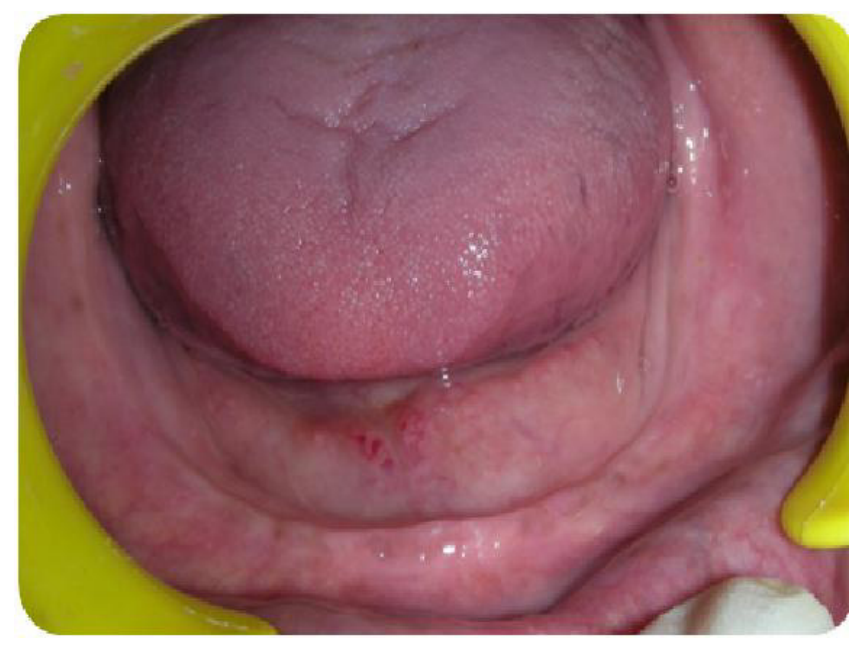

Fig 2. Resorbed mandibular ridge

\section{Clinical technique}

\section{Preliminary and secondary impressions}

The preliminary impressions were made in stock tray with a mucocompressive material, impression compound. (Fig. 3). The secondary impression was made in special tray with low viscosity mucostatic material, zinc oxide eugenol. (Fig. 4 \& 5)

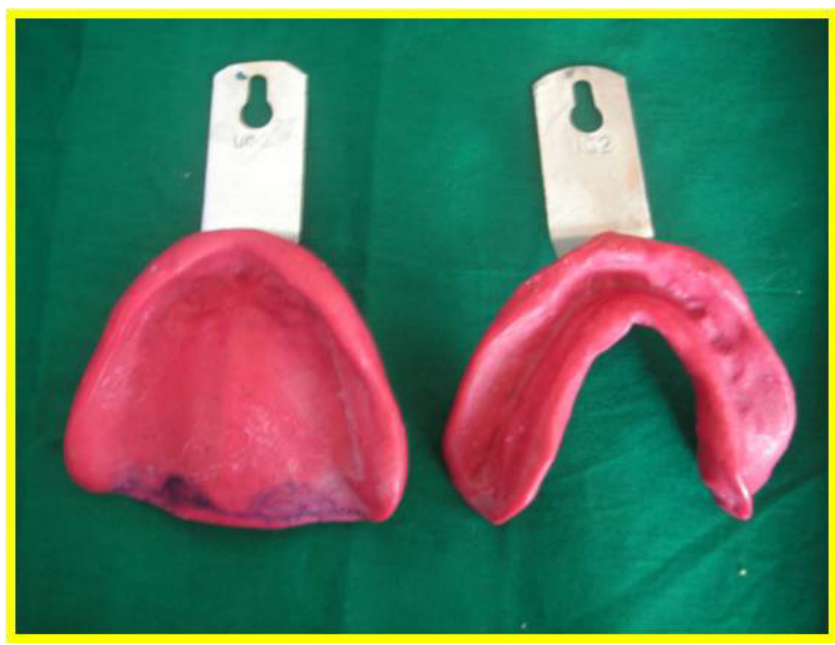

Fig 3. Maxillary and Mandibular Primary Impression
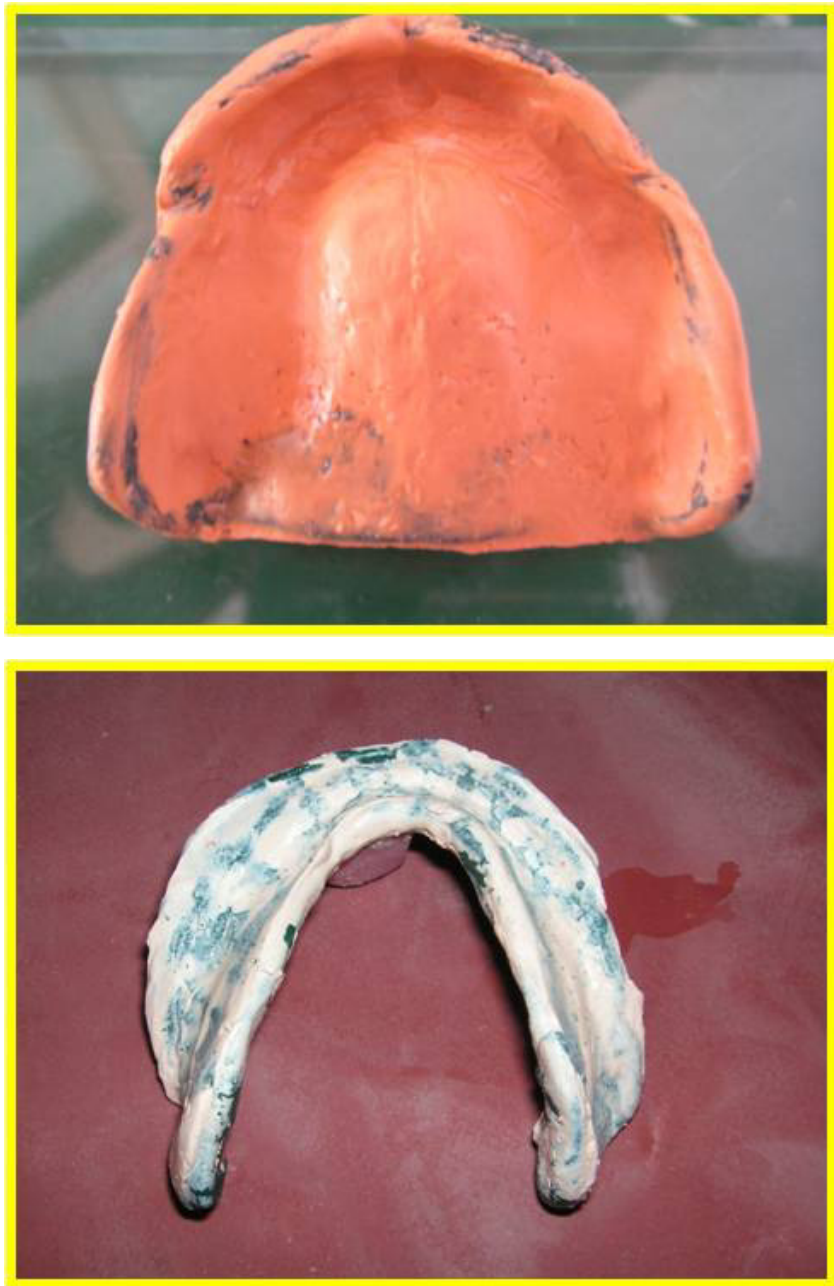

Fig $4 \& 5$. Final Impressions 


\section{Jaw relation}

The occlusal rims were made on heat cured acrylic record denture bases for increased stability. The record base was assessed for extension, comfort and stability. The maxillary occlusal rim was shaped properly to provide good support for the musculature labially and buccally. It is vitally important that the occlusal rim was correctly shaped in its height and width; otherwise

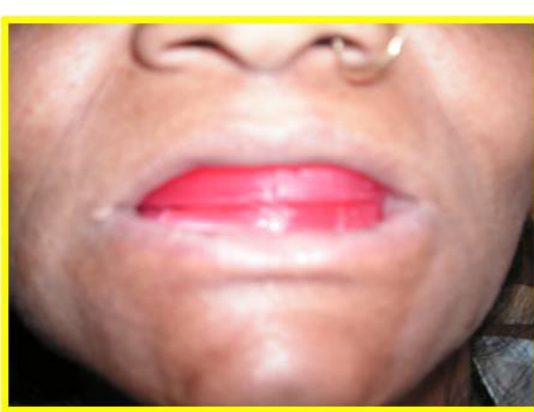

Fig 6. Jaw Relation the correct width of the mandibular arch cannot be developed. After establishing the correct maxillary occlusal planethe mandibular occlusal rim was adjusted to the correct occlusal vertical dimension. (Fig. 6). The established jaw relation record was then mounted on a mean value articulator.

\section{Modification of mandibular record base}

The occlusal rim was removed from the mandibular record base and a superstructure was constructed on it. Numerous designs of superstructure have been

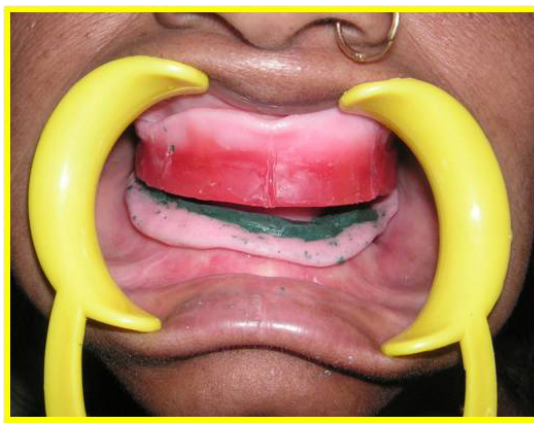

Fig 7.Establishing the Correct Occlusal Height with Low Fusing Compound suggested in the literature but the one used here was made of low f $u$ s $\quad$ i $n$ g i m pres s i o compound. The low fusing i m press io $\mathrm{n}$ c o m p o u n d superstructure had two vertical pillars in the posterior region that maintained the contact with the maxillary rim. In rest of the region it was slightly short of the vertical to allow space for the neural zone impression material. (Fig. 7). The superstructure served two functions:

- Provided occlusal stops at correct vertical dimension of occlusion.

- It provided support to the neutral zone impression material.

\section{Neutral zone impression}

Patient was made to sit upright with the head unsupported to allow actions of swallowing and speaking to be more natural. Maxillary wax rim was inserted in the mouth and reassessed for support \& occlusal plane. With the mandibular record base out of the mouth, tissue conditioner (GC Company) was mixed according to manufacturers instructions and the correct volume of

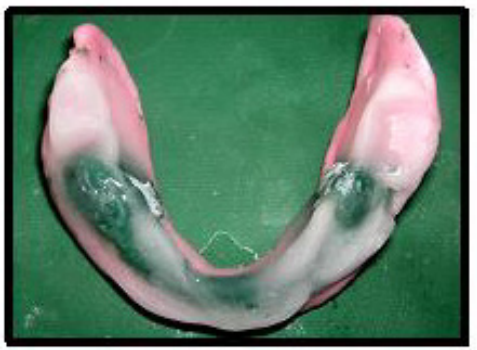

Fig 8.Completed Neutral Zone Impression it was placed on the superstructure. Tissue conditioner was manipulated to form an approximate rim and the mandibular record base was inserted in the mouth. The volume of tissue conditioner was controlled so that the sulci are not distorted. The patient was instructed to perform repeated actions:

- Swallow and take sips of water

- Talk aloud, pronouncing vowels and count from 60 to 70

- Smile, grin, lick their lips

- Protrude the tongue

\section{- $\quad$ Pout/purse the lips}

These actions moulded the material by muscle activity. After $10 \mathrm{mins}$, the set impression was removed from the mouth. (Fig. 8).

\section{Laboratory stage}

The neutral zone impression was replaced on the master cast and orientation grooves were made on the base of the cast, on buccal as well as lingual side.

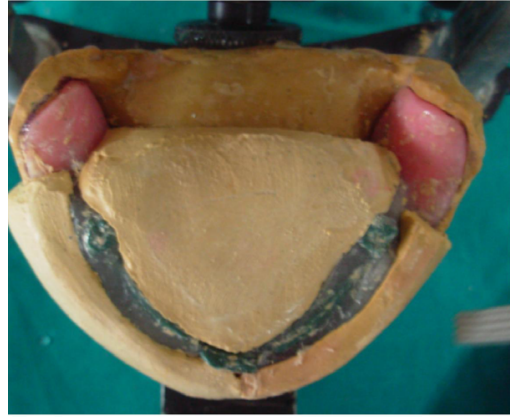

Fig 9. Plaster Index made around Neutral Zone Impression
On the buccal side the plaster index was made in two parts separated at the midline for ease of removal and replacement. On the lingual side the index was made as a single piece. (Fig. 9). The tissue conditioner impression \& the low fusing compound was removed and the plaster index was replaced. (Fig. 10) Wax was then poured in the space which represented the neutral zone forming the new occlusal rim on the mandibular record base. Teeth arrangement was done exactly following the index. Posterior teeth had to be trimmed slightly lingually to conform in to the neutral zone. Due to uncertain pattern of mandibular closure it was decided to use 


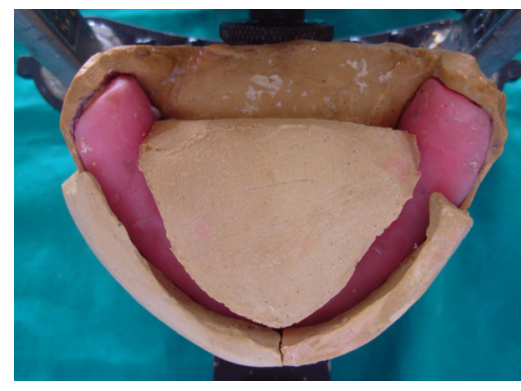

Fig 10. Neutral Zone Impression removed to build wax occlusal Rim

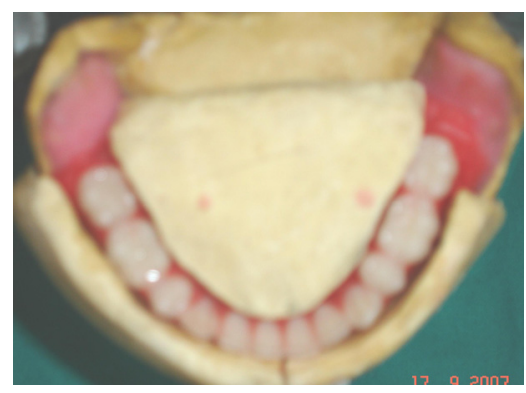

Fig 11. Teeth arrangement done following Plaster Index mo n o p l a n e occlusion concept. Teeth arrangement was checked again by putting the plaster index around the wax tryin. (Fig. 11).

\section{Completion of} denture

The waxed up dentures were placed in the mouth and patient was asked to repeat all the $\mathrm{mov}$ e m e n t s p r e vi o u s l y mentioned. The denture was stable after all the movements. The dentures were then processed as a conventional denture. Finishing and polishing of denture was done carefully so that the contour of the polished surfaces remained unaltered.

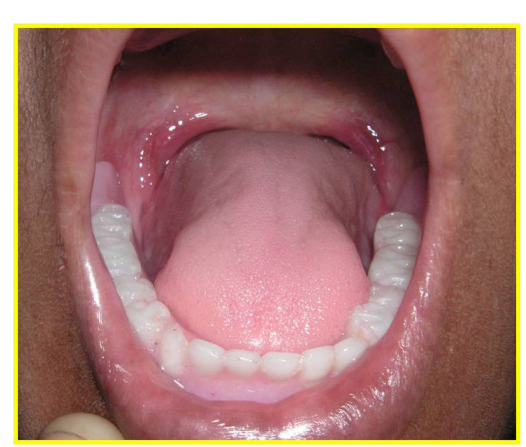

( $\mathrm{F}$ i g. 12 ). O n insertion of denture, minor

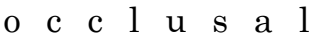
discrepancies were corrected. (Fig. 13)

\section{Advantages}

A denture made using the neutral zone impression

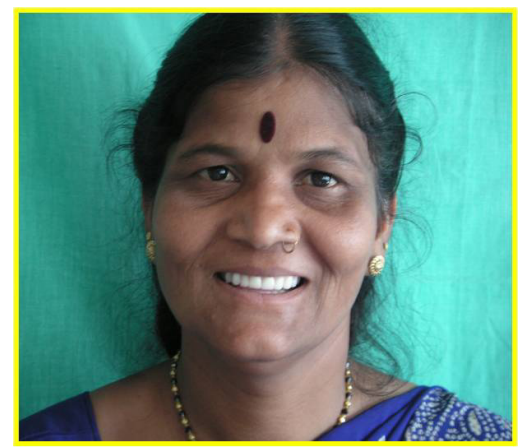
technique provided the following advantages-

Fig 13. Post denture insertion

Fig 12. Teeth Positioned in the Neutral Zone in Final Denture

- I m p r o v e d stability and retention.

- Posterior teeth were correctly positioned allowing sufficient tongue space.

- Good esthetics due to proper support of underlying musculature.

\section{Summary and conclusion}

Neutral zone impression technique is very effective in highly atrophic ridge providing stability and retention. This technique uses muscle function to produce the impression. It defines the polished surface and teeth position. This technique requires a extra clinical stage \& good communication with the technician. ${ }^{1}$ The neutral zone approach has also been used in patients who have had a partial glossectomy, mandibular resections or motor nerve damage to tongue- which have led to either atypical movements or unfavourable denture bearing area ${ }^{6}$

\section{References}

1. M.J.Gahan and A.D. Walmsley. The neutral zone impression revisited. Br Dent J 1985; March 2005, 198(5):269-72.

2. Victor E. Beresin and Frank J. Schiesser. The neutral zone in complete dentures-principles and technique, Reprint 1973, C.V.Mosby company.

3. Basker RM,Harrison A. A survey of patients referred to restorative dentistry clinics. Br Dent J 1981; 64:105-8.

4. Atwood D A, Post extraction changes in the adult mandible as illustrated by micrographs of midsagittal sections and serial cephalometric roentogenograms. J Prosthet Dent 1963;13: 810-24.

5. Okhuoo C, Hanatani S, Hosoi T. Mizuno Y. Neutral zone approach for fabrication for a partial glossectomy patient- A clinical report. J Prosthet Dent 2000; 84:390-93.

6. Fish E.W an analysis of the stabilizing factors in denture construction. Br Dent J 1932; 52:599.

7. Fish E.W. Using the muscles to stabilize the full denture. JAm Dent Assoc 1933; 20:2165-65. 